\title{
O museu e sua função socioeducativa: o caso do museu de arte do Rio Grande do Sul Ado Malagoli (MARGS)
}

\author{
Otávio Augusto Diniz Vieira*
}

Resumo: O presente trabalho é baseado na experiência de estágio supervisionado realizado no Museu de Arte do Rio Grande do Sul Ado Malagoli - MARGS. É desenvolvido um projeto de intervenção que leva ao museu os alunos do terceiro ano do Ensino Médio da Escola Estadual Florinda Tubino Sampaio, o qual tem como objetivos reconhecer o museu como uma organização cultural complexa e, principalmente, sensibilizar os alunos-visitantes para o espaço museológico, despertando o interesse para futuras visitações aos mais diferentes museus. Aspectos como a capacidade de geração de ambiência, local onde as trocas pedagógicas possam ser catalisadas; a complexidade museológica, que se baseia no conhecimento multidimensional; e, finalmente, o modo mais adequado para a realização de uma visita pedagógica, o qual se baseia no diálogo com o público e no "sentir-se" bem, são desenvolvidos teoricamente. Através de uma pesquisa com os alunos, discute-se o paradigma das visitações limitadas às salas de exposição.

Palavras-chave: Visitação ao MARGS, geração de ambiência, complexidade; museologia.

Abstract: The following article is based on the experience of the supervised trainee held at the Art Museum of Rio Grande do Sul (MARGS). It is developed an intervention project that takes students of the third year of High School of the State School

Mestrando em Geografia pela Universidade Federal do Rio Grande do Sul (UFRGS), graduado em Turismo pelas Faculdades Rio-Grandenses (FARGS) e artista plástico. E-mail: otavio_vieira@hotmail.com 
Florinda Tubino Sampaio for a visit, which aims to recognize the museum as a complex cultural organization and, especially, to sensitize the visitor-students to the space of the museum, awakening the interest for future visitations at the different museums. Aspects such as the ability to generate ambience, where educational exchanges can be catalyzed, the museum complexity, which is based on multidimensional knowledge, and finally, the most appropriate way to conduct an educational visit, which is based on dialogue with the public and the "feeling" well; are theoretically developed. Through a survey with the students, it is discussed the paradigm of the visitations limited to the exhibition rooms.

Keywords: Visit to MARGS, ambience generation, complexity, museology.

\section{Introdução}

O MARGS é o mais importante museu de arte do Rio Grande do Sul, está localizado no centro de Porto Alegre, na Praça da Alfândega, e tem nas suas proximidades outros importantes centros culturais, como o Memorial do RS, o Santander Cultural e a Casa de Cultura Mario Quintana. O principal foco de atuação do MARGS é a arte moderna e contemporânea do Rio Grande do Sul; entretanto, outros reconhecidos artistas nacionais e internacionais também integram o acervo do museu.

O presente trabalho foi realizado durante o estágio de conclusão do curso de Turismo das Faculdades Rio-Grandenses desenvolvido no Museu de Arte do Rio Grande do Sul Ado Malagoli - MARGS. Tem como objetivo diagnosticar as caractarísticas organizacionais desse museu e, através da proposta de intervenção, sensibilizar os alunos de escolas de Ensino Médio e Fundamental para a visitação orientada no MARGS e em outros museus. Nesse sentido, foi desenvolvido um projeto que intervém no modo como essas visitações são realizadas. 
O aumento do turismo pedagógico nos últimos anos é um aspecto bastante notável, e junto a ele deve ser criteriosamente pensado onde e como esse turismo será realizado. ${ }^{1}$

Museus são instituiçỗes por si só educativas, porém, opostamente a esse aspecto, alunos dos níveis de Ensino Fundamental e Médio mostram certo desinteresse e desinformação sobre esses ambientes. Este trabalho pretende, principalmente, criar nesse público composto por alunos-visitantes, através de um maior conhecimento de tais organizações, um satisfatório nível de interesse, que os faça ter vontade de retornar e visitar outros museus da cidade e do mundo.

Foi observado, durante as rotineiras idas de escolas ao MARGS, que os alunos se limitam a visitar as exposições as quais estão sendo exibidas, deixando de lado importantes características desse espaço. Sendo assim, uma visitação que agregue os mais diversos departamentos certamente causariam uma impressão diferente nessses alunos-visitantes, no sentido de estimulá-los a melhor compreender os espaços museológicos e motivá-los a futuras visitações, seja ao próprio MARGS ou a outros museus, da cidade e do mundo.

As atividades realizadas durante o período de estágio foram essenciais e resultaram num amplo conhecimento dos espaços do museu e de suas características mais relevantes, o qual foi utilizado durante a elaboração do projeto de intervenção. Essas características são de fundamental importância, pois o projeto visa mostrar aos alunos-visitantes além das exposições que estão sendo exibidas no momento, também toda a complexidade do museu, desde a história de seu edifício e sua fachada até os núcleos institucionais, onde diversas atividades são realizadas cotidianamente.

Museus são excelentes espaços para a livre troca de ideias, é o lugar onde professor e aluno desempenham o mesmo papel, o de descobridores; museus não são ambientes de ensinamentos mas

1 “Turismo pedagógico é aquele quando o aluno desloca-se de seu local diário de estudos com o objetivo de desenvolver uma atividade educativa em outro ambiente. É uma forma de propor ao aluno uma participação ativa no processo de construção do conhecimento" (MOLETTA, 2003, p. 11). 
de descobertas. Por essa razão, são ideais espaços para a geração de ambiências, é onde os alunos conseguem catalisar o processo educativo, através da forte interação que eles têm com o ambiente. ${ }^{2}$

O MARGS está localizado no centro da cidade de Porto Alegre, onde "concorre" com outros museus, muitos de arte contemporânea, e por isso, de maior interesse para o público jovem. É nesse contexto que este trabalho pretende desenvolver um evento que aborde todos os aspectos do museu, transformando então a visita em um momento marcante e que possa se refletir por toda a vida desses jovens e promissores visitantes.

\section{O Museu e seu Poder de Geração de Ambiência}

Os museus são organizações que têm excelentes e ideais espaços para a criação de momentos de trocas culturais. Os profissionais que trabalham nos museus devem criar momentos onde os membros de todas as classes sociais e idades possam gerar conhecimentos, os quais fora desse espaço dificilmente teriam a possibilidade de gerar.

Foi no começo do século XIX, quando Napoleão Bonaparte abriu o museu Louvre para a visitação do público em geral, sem que fosse necessário nenhum tipo de abono financeiro para o ingresso ao museu, que o debate sobre o papel social dos museus teve início. Assim, como nos comenta Barreto:

$\mathrm{O}$ primeiro museu a revolucionar esse relacionamento com o público foi o Louvre, entre 1795 e 1799. O Louvre surgiu como resultado da estatização das coleçốes da realeza e do clero após a Revolução Francesa e foi aumentado com os saques de

2 "O significado do termo ambiência deseja remeter, no presente caso, a uma noção de espaço geográfico como um sistema composto por relaçốes sociais articuladas a relaçôes físico-sociais, espaço condicionador da existência humana e, que pode, este espaço, ser eleito como objeto catalisador de açóes transformadoras exatamente por esse motivo - por ser condicionador da existência humana” (REGO, 2006, p. 10). 
guerra de Napoleão. Foi considerado o "museu do povo", onde qualquer pessoa podia visitar sem pagar. Seu objetivo era educar as pessoas, ou seja, inserir os valores burgueses pós-revolução (2001, p. 64).

O principal objetivo do imperador era divulgar todo o seu poderio militar e suas conquistas ao longo dos anos, ou seja, nada mais que a sua própria promoção; porém, ao mesmo tempo em que conseguiu promover-se com tal ação, também possibilitou a divulgação da cultura artística, a qual anteriormente era exclusividade da elite.

Napoleão Bonaparte gerou, então, nesse momento, o ambiente necessário para a divulgação de uma cultura anteriormente elitizada, e possibilitou assim o contato com obras de arte para um público que nunca tinha experenciado tal momento. Essa ocasião certamente foi de fundamental importância para certas pessoas, futuros artistas, que caso não tivessem tido tal oportunidade de entrar em contato com obras de arte, deixariam assim seus talentos artísticos escondidos por toda uma vida.

Porém, desde a época napoleônica até os nossos tempos, muitos anos já se passaram. Atualmente um dos principais papéis dos museus é divulgar suas obras de arte para todos os tipos de públicos, sejam esses favorecidos economicamente ou não. A motivação para deslocar-se a visitar um museu também fica muitas vezes escondida em jovens das altas classes sociais, pois tendo em vista todos os desenvolvimentos tecnológicos que fazem com que as novas gerações fiquem cada vez mais em casa, usando seus já modernos computadores ou vendo suas "antigas" televisões, o interesse pela arte e pelo "mostrar" artístico, que está dentro de cada um de nós, é deixado de lado.

Diante dessa evidência, compreende-se que ressignificar os espaços dos museus através de situações diferenciadas, promovendo alternativas além das já estabelecidas, gerando ambiências, é fundamental para um contínuo interesse aos espaços museológicos.

A geração de ambiências são momentos criados para catalisar as trocas culturais, são momentos específicos que mesmo 
sendo de curta duração, poderão, caso tenham sido relevantes, se manter retidos na memória de cada um por um tempo indeterminado. São experiências práticas e não teóricas, pois como destaca Rego (2006, p. 197), "os conceitos que articulam o conceito de geração de ambiência pertencem, de fato, ao domínio da práxis, porque são construções de parcerias dialógicas”.

Em um projeto realizado pela professora Roselane Jordão Costelle, Mestra em Geografia pela UFRGS, em uma escola pública e outra privada da cidade de Porto Alegre, foi pedido para que os alunos construíssem maquetes sobre o ambiente onde estão inseridos. Nesse contexto, concluiu-se que:

A maquete do grupo de alunos da escola particular apresenta características de que o espaço vivido ou familiarizado desses alunos representa uma leitura virtual, baseado em projetos de computador ou em programas de televisão, enquanto o grupo da escola pública tem como o seu espaço vivido o cotidiano de uma cidade real.

[...] reforça-se o conceito de identidade: a identidade do aluno como subjetividade, resultante de sua ambiência; e a identidade de lugar, parte de um espaço que conserva sua singularidade. Assim, quando o aluno manifesta uma representação espacial, ele reflete tanto a sua identidade quanto à identidade do lugar, ambas são diferentes, mas tendem a se completar (COSTELLE, 2003, p. 147).

É importante ter em conta os distintos níveis sociais dos alunos que visitam o museu e as diferentes características de percepção do espaço que apresentam entre si. ${ }^{3}$

Adolescentes com um maior nível social têm uma visão de espaço mais global, em geral conhecem pouco do entorno em que estão inseridos, isso se deve à forte relação que eles têm com os computadores, a tecnologia de ponta e o mundo globalizado, e por sua vez, veem a cidade apenas da perspectiva de dentro do carro de seus pais, tendo poucas experiências de caminhar pela cidade e reconhecê-la com seus próprios olhos. Nome e localização das praças mais importantes, monumentos, prédios

3 Nesse artigo, entende-se, por nível social, a influência que a condição socioeconômica dos alunos tem em relação aos espaços que esses frequentam e percorrem. 
históricos e pontos de referência na cidade são por muitas vezes desconhecidos desses alunos. Entretanto, como constata Costelle:

[...] os alunos em idade escolar de menor nível social costumam caminhar pelo centro, pegar ônibus, ir e voltar da escola caminhando praticamente todos os dias, além de várias outras atividades lúdicas e livres pela cidade, onde têm a oportunidade de conhecer bem o entorno; apresentam assim uma visão mais realista da cidade, de seus problemas e possíveis soluções (COSTELLE, 2003, p. 148).

Essas duas diferentes percepções são importantes para que se possa direcionar a visitação ao museu de forma mais interessante e pedagógica, de modo a manter estrito relacionamento com as diferentes experiências que cada grupo de alunos costuma vivenciar.

A criação de momentos de novas aprendizagens, como essa citada, é a principal função social dos museus. Muitos momentos podem ser criados e muitas classes sociais podem ser levadas aos museus para experenciarem, aprenderem e verem coisas novas, as quais muitas vezes nem em seus sonhos estavam presentes. Sensibilizar os mais diversos tipos de público para a as artes, como pinturas, esculturas, fotografias e outras é de fundamental importância para a divulgação da cultura local e para o desenvolvimento das habilidades artísticas que podem estar escondidas dentro dos jovens.

Os museus são excelentes espaços para a criação de ambiências, e perder esses espaços em detrimento de objetivos pessoais, incapacidade e/ou desconhecimento profissional, é deixar de estar criando oportunidades para o desenvolvimento pessoal de vários grupos sociais, os quais apenas naquele ambiente poderiam experenciar certas situaçốes e desenvolver determinadas qualidades. São instituições onde momentos de trocas culturais devem ser diariamente criados e estimulados, para que a relação entre os visitantes e a arte possa ser mais íntima. 


\section{História da evolução museística e sua função social}

Tanto os museus surgidos na antiguidade grega quanto as coleções surgidas no Oriente no século X e no Ocidente no século XVI foram criadas pela realeza, pelo clero, pela nobreza ou pela burguesia. Somente no século XX a questão do papel social dos museus começou a ser discutida, e em meados desse século tais instituições começaram a procurar um futuro útil para si mesmos. Barreto nos comenta que:

As modificações vieram apenas nos anos setenta, em virtude da crise que os museus enfrentavam, devido a uma revisão de conceitos na área da antropologia. A partir dos anos trinta, essa ciência que se apoiava muito em evidências da cultura material começou a interessar-se pela pesquisa de campo e pelo estudo do comportamento dos grupos étnicos, e os museus passaram a ser praticamente desnecessários para os antropólogos" (BARRETO, 2001, p. 62).

Os museus começaram a buscar então uma ruptura com os museus tradicionais, inovando e redimensionando sua função pedagógica e social, além de intensificar as relaçôes com o público. Logo, os museus de arte foram os primeiros a despertar para a necessidade de "educar para ver", pois, para atrair um público que nunca tinha tido a oportunidade de conhecimento das artes plásticas, era preciso educar para torná-lo interessante e atrativo.

$\mathrm{O}$ primeiro a fazer as rupturas iniciais com os conteúdos formais tradicionais dos museus foi o museu de Anacóstia, localizado num distrito negro de Washington. Foram então utilizadas técnicas museísticas para conscientizar a população sobre seus problemas cotidianos e mostrar possíveis soluçôes. A primeira exposição foi sobre ratos, já que os roedores constituíam o principal problema no bairro, e a segunda foi sobre a criminalidade.

No período pós-revolução cultural de 68 os museus passaram a tratar de temas do cotidiano e das "minorias" historicamente silenciadas. Surge assim então uma proposta de museu pluralista, onde todos os segmentos da sociedade se sentissem representados. 
O primeiro foi o Museu Antropológico do México, que tinha como objetivo explicar a história e os costumes do país, e as exposições estavam pensadas para um público em sua maioria analfabeto, baseando-se apenas em imagens e elementos plásticos.

Assim, após séculos que os museus refletiam a vaidade de seus donos, atualmente procuram mostrar os objetos da cultura de forma crítica e tenta permitir o "diálogo" do público com um objeto contextualizado que ele compreenda.

No século XVII, somente viajantes distintos e cientistas podiam apreciar as coleções. Já a partir de 1700 alguns museus europeus importantes permitiram a entrada de público mediante o pagamento de uma taxa, porém a grande maioria ainda só permitia a entrada de especialistas, estudiosos e estudantes.

$\mathrm{Na}$ Inglaterra, onde até meados do séc. XIX não se deu apoio aos museus, argumentando-se que "não era de incumbência de Sua Majestade dar luxos ao povo" (HUDSON apud BARRETO, 2001, p. 64).

O relacionamento dos museus de ciência com o público passou por três etapas, como classifica Barreto:

A primeira em que as coleções eram apenas o material didático; já na segunda se utilizavam diagramas e modelos com movimento para ilustrar o processo de funcionamento das máquinas; e a terceira os museus se tornaram um local de experimentação científica (hands on). (BARRETO, 2001, p. 65).

Outra tendência atual é a de complementar todos os acervos com um estudo da sociedade em que está inserido. Os museus de indústrias começaram, na década de 70, na Europa Ocidental, a incorporar também a história social da industrialização.

Dos museus de arte, espera-se que deixem de ser templos para connaisseurs. Uma das propostas para aproximar mais o público das obras de arte é o melhor conhecimento do artista. No museu de David D'Angers, na cidade de Angers, na França, se mostra todo o processo de confecção da obra de arte: as ferramentas, os modelos, os recibos de pagamento. 
Já a renovação dos museus de história acontece quando param de ser apenas depósito de matéria-prima e passam a ser um local onde o historiador interpreta os objetos e relata uma história inteligível.

Hoje, é importante que não se privilegie determinado segmento da sociedade. Se antes, apenas objetos pertencentes à classe dominante eram retratados, excluí-los e colocar só objetos dos dominados, é reproduzir o modelo. Ambos os setores e suas contradições devem ser retratados.

Sobre o papel que os museus devem desempenhar na sociedade, Barreto comenta que:

Nas décadas de 70 e 80 as discussóes acerca do papel social dos museus se inflamam, e houve uma cobrança muito grande para que tivessem alguma utilidade na promoção de mudança social. Fica claro, no entanto, que os museus não têm poder para mudar as injustiças; só podem mostrá-las e discuti-las. Entretanto o Museu Nacional do Níger ou o de Tacubaya, no México, mostram o contrário, e são centros comunitários de assistência social (BARRETO, 2001, p. 66).

Essa ideia não é compartilhada pela maior parte da comunidade museológica, pois o papel social dos museus não pode ser dissociado da motivação de seus visitantes, que é, na maioria dos casos, educação, aquisição de cultura, entretenimento ou divertimento. Museus como os anteriormente citados estariam suprindo a carência de instituições específicas em solucionar os problemas socioeconômicos locais.

\section{O papel dos museus na atualidade}

Os museus e o patrimônio histórico e cultural são o atrativo/recurso turístico por excelência. Logo do desenvolvimento do turismo moderno, os museus eram considerados como uma tarefa quase sagrada, e desde então existe uma certa obrigação de visitação, como também aos cemitérios e igrejas.

Houve uma grande transformação dos museus desde o início do século XX, transformação essa que coincide com o crescimento 
do fenômeno turístico, já que os turistas naturalmente pedem museus, onde eles possam, dessa forma, conhecer algum tipo de legado cultural local, seja uma representação da cultura atual ou então um legado dos antepassados da localidade visitada.

Os museus assim deixaram de ser apenas depósitos de coisas velhas, para então concentrar-se mais na história a ser contada que no objeto a ser mostrado; objeto se torna então um meio para contar a história e não o foco principal. $\mathrm{O}$ que interessa aqui é, assim, mostrar o significado do objeto, por isso o artista tenta da melhor maneira possível explicá-lo, colando textos explicativos, identificando o material e a técnica usada, etc.

A mensagem a ser passada para o público começou então a ser transmitida de um modo mais dinâmico, seja de formas lúdicas, onde técnicas de parques temáticos são muitas vezes utilizadas, assim como recursos de multimídia e recursos tecnológicos.

Sobre a oferta, as novas tecnologias aplicadas nos museus contemporâneos e suas relações econômicas, Barreto comenta que:

Por longos anos o trade turístico valorizou apenas os museus mais consagrados, hoje a oferta é quase ilimitada, e museus de todos os tipos são incluídos nos roteiros culturais. Essa oferta deveu-se muito ao desenvolvimento de museus auto-sustentáveis, pois a introdução de novas tecnologias teve que ser acompanhada com uma questão econômica mais forte, para que fosse possível criar e manter tais museus (BARRETO, 2001, p. 54).

Se os curadores e diretores continuassem seguindo a economia de mercado e esperando subsídios do estado, provocariam seu fechamento. Foi então que formas de arrecadar fundos para o museu começaram a ser pensadas, tais como venda de ingressos, souveniers, réplicas, organização de cursos e oficinas, além da oferta alimentar (bares e restaurantes) que comumente podem ser encontrados no espaço do museu. Curadores e diretores imaginavam que o patrocínio de empresas privadas poderia transformar os museus em feiras e o turismo, num parque de diversão.

Porém, é importante destacar que os museus têm sólida base científica para apresentar suas exposições, além de terem uma função educativa; e mesmo que um museu se utilize de técnicas de 
parques temáticos, como é o caso do Parque Oceânico Cousteau, a informação que o visitante recebe provém nada menos que de Jacques-Yves Cousteau, o maior pesquisador da vida marinha.

\section{Educar para Ver e a Visita Orientada nos museus}

Orientação significa, antes de tudo, abertura ao diálogo e disposição à descoberta de possibilidades sempre renovadas de encontro, encontro entre o museu e seu público e entre esse público e as obras em exposição. Sobre esse tema Amaral nos comenta:

Quando se fala de orientação, não se trata apenas de saber onde está o Norte ou o Sul. O que um museu pretende com o serviço de visitação orientada é até mesmo o contrário do que se entende por orientação quando se tem em mente a bússola, ou sinalizaçóes que apontem direçóes pré-determinadas. (AMARAL, 2008, p. 1).

A primeira questão a ser colocada pelo pessoal que participa da organização de um museu é a de como atrair o visitante. Por que alguém deveria ter o interesse em ir a um local assim? Amaral responde tal pergunta dizendo:

É claro que se pode sempre ressaltar a importância cultural ou o valor pedagógico das exposiçôes, mas o fato é que o sentir-se bem, o sentir-se à vontade e a possibilidade de desfrutar com prazer o que está sendo oferecido, se colocam como motivaçôes fundamentais. É para isso, para tornar prazeroso e frutífero o encontro dos visitantes com o museu e com as obras que estão à sua espera, que são organizadas as visitas orientadas. (AMARAL, 2008, p. 1).

No MARGS, esse trabalho é realizado junto com voluntários, que são chamados de orientadores. Entretanto, há varias outras nomenclaturas utilizadas para o mesmo trabalho em diferentes museus e países; alguns exemplos são, guia, facilitador do diálogo, monitores, mediador ou ainda, como utilizam na França, animateur, que significa animador. 
A partir dessa nomenclatura usada na França, observa-se que muitas vezes o orientador designado a mostrar o museu e suas exposições deve atuar de maneiras diferenciadas, dependendo do público que está recebendo. Logo, para um público de crianças ou pré-adolescentes, o orientador, ou animateur, pode atuar como atua um ator, ou mesmo um palhaço, visto que o objetivo é atrair a atenção do público e tornar a visitação divertida. Para tal fim, inventar e contar histórias - como a seguir mostradas - para crianças, pode ser uma atividade pedagógica de extrema valia.

Dizem por aí que o MARGS é um castelo onde mora uma Dama de Branco e um Homem com um Gato Preto. De dia eles dormem dentro de quadros que ficam pendurados nas paredes; de noite passeiam pelo terraço onde os pombos vêm dormir. Ah, e o título do poema, é você quem dá”.

por que um museu?

perguntou a musa do dicionário

porque é necessário respondeu

tem que ter

um lugar um lugar um lugar

onde ver cabe dentro do olhar

que mancha vira rinoceronte

janela porta para outro horizonte

hoje nunca esquece de ontem

e mármore flutua mais leve que o ar

um lugar sem pressa

que os azulejos contam uma história

e as escadas, encantadas

levam ao mundo dos contos de fada

onde a emoção exata de um tigre

salta da xícara para o pires

e uma idéia, na sua forma alada mais rara

surpreenda o visitante e encontre um coração 
um lugar...

que quando todos vão embora

e tudo fica completamente a sós

o vento que vem de lugar nenhum

sopra pelos corredores

as esculturas ganham vida

os personagens descem dos quadros

seguem todos para o grande salão

e lá reunidos, se divertem, dançam

fazem piadas a sós

Poeta: Alexandre Brito

Artista: Eduardo Vieira da Cunha Poeta

Fonte de ambas: Revista do MARGS (Dez, 2007, nº 0, p.15)

Figura: Personagens que ganham vida

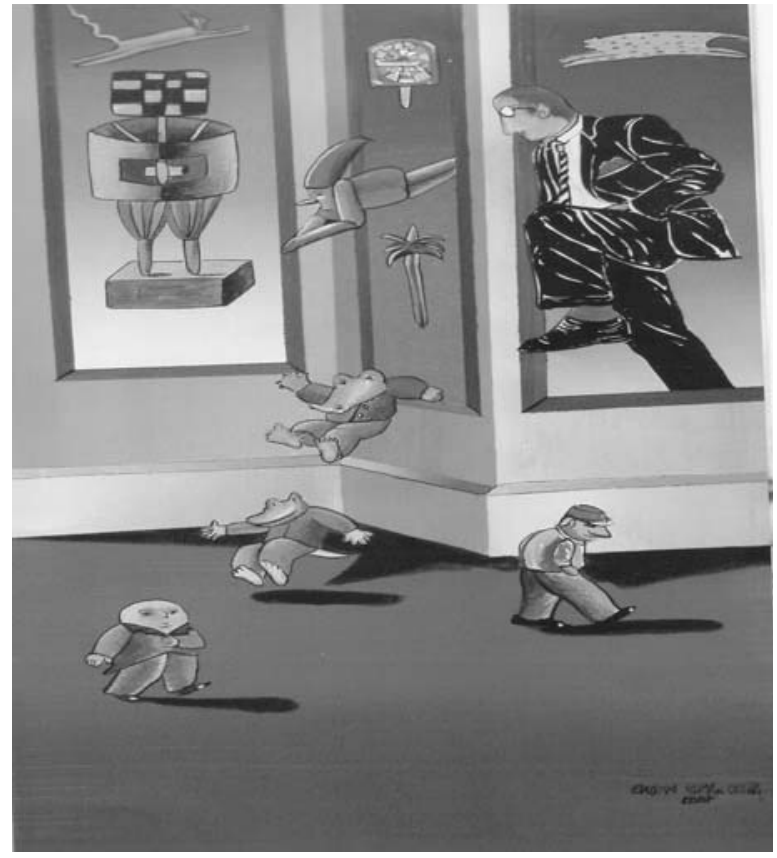


Sobre o relacionamento público-museu, Amaral (2008, p.1) afirma que "não se trata de trabalhar para o público, mas com o público". Isso só se efetiva se houver um contato ativo entre as obras e as pessoas. Essa é a grande motivação de todas as equipes que mantém o museu em funcionamento, no lugar de despejar "cultura" no público, esse pessoal contribui para a criação do ambiente no qual os visitantes se expressam através dos objetos que descobrem. Assim:

[...] do que se trata é não de dar aulas ou entulhar os ouvidos do público com informações, mas de propiciar que ele efetivamente se encontre com o museu e com suas obras, o que só ocorrerá na interação. Uma interação entre quem vê e aquilo que é visto que, certamente, pode ser apoiada com orientaçóes que se façam necessárias, contanto que a iniciativa do visitante não seja tolhida, mas estimulada. (AMARAL, 2008, p.2).

Por isso, a posição dos orientadores deve ser daqueles que se colocam à disposição para acompanhar as visitas ao museu e fornecer orientaçốes, não para dar aulas e muito menos para se colocar entre o visitante e a obra. Sua tarefa é, antes de tudo, a de receber como convidados sempre bem-vindos aqueles que chegam ao museu, dando-lhes as boas-vindas, colocando-os à vontade e os estimulando para que aproveitem a visita. O orientador aproxima os visitantes e as obras, para que se entendam e possam dialogar, além de fornecer dados sobre o museu e suas funções.

A relação entre o espectador e a obra é semelhante a que se processa em um diálogo, é uma interação em que tanto a percepção quanto a imaginação do espectador têm papel ativo. Por isso, e para isso, o orientador sugere possibilidades de abordagens, sem fixar um caminho único. Ele não ensina uma maneira de "ler" a obra, nem comunica ao espectador o que ele "deve" ver naquilo que está vendo. O orientador não ensina coisa alguma, ele está aí para ajudar a abrir caminhos. Da mesma forma, mais do que repassar informações, cabe ao orientador lidar com as informações que o público já possui, ir ao encontro do espectador para estimulá-lo e auxiliá-lo. Mais do que ocupar o tempo da visita com sua fala, cabe ao orientador abrir espaço e estimular o visitante a falar. 
Logo, o primeiro momento da proposta foi desenvolvido na própria sala de aula, e teve como objetivo criar nos alunos uma expectativa para a visitação, que foi realizada exatamente uma semana mais tarde. Nessa oportunidade, os alunos r-eceberam orientações sobre a visita, tais como: um breve histórico e localização do museu, explicação sobre as atividades que seriam desenvolvidas no MARGS e uma breve conversa teórica sobre "maneiras de ver" e "maneiras de não ver", através da atividade "Motivando o olhar", baseada na palestra ministrada por Amaral, durante o I Encontro de Formação de Orientadores do MARGS, realizado nos dias 3 e 4 de abril de 2008.

A atividade "motivando o olhar" (Anexo I) foi criada para ser desenvolvida dentro da sala de aula, na semana anterior à visitação, como parte da primeira etapa do projeto de intervenção (tanto a atividade como o projeto serão descritos mais adiante no artigo).

\section{Complexidade Museológica}

O museu, quando visitado pelas pessoas, sejam turistas ou transeuntes que decidem entrar para "dar uma olhada", é observado de uma ótica fragmentada, onde geralmente a visita se resume na observação das exposições que estão sendo mostradas. Essa parte, dita ser a mais importante, muitas vezes não estimula suficientemente esses visitantes ao ponto de criar a motivação para um retorno a esse ambiente.

Esse aspecto é de extrema importância e deve ser cuidadosamente observado pela comunidade museológica quando essa recebe estudantes. Os interesses dos alunos em idade escolar são muito diversos; assim, esses diferentes interesses devem ser, da melhor maneira possível, atendidos durante uma visita a um museu.

[...] de fato, a aspiração à complexidade tende para o conhecimento multidimensional. Ela não quer dar todas as informações sobre um fenômeno estudado, mas respeitar suas diversas dimensões: assim como acabei de dizer, não devemos esquecer que o homem é um ser biológio-sociocultural, 
e que os fenômenos sociais são, ao mesmo tempo, econômicos, culturais, psicológicos etc. Dito isso, ao aspirar a multidimensionalidade, o pensamento complexo, comporta em seu interior um princípio de incompletude e de incerteza. (MORIN, 2003, p. 177).

Um museu de arte, como é o caso do MARGS, pode contar muito além do que a história da arte; esse espaço possibilita o desenvolvimento da interdisciplinaridade.

Por exemplo, contextualizar a história da época da construção do prédio, isso nos remete há cem anos e essa história pode e deve ser contada. Os museus são também instituições que necessitam de um considerável aporte financeiro para a realização de suas atividades; necessitam de um núcleo que divulgue essas atividades; de compra de obras para o acervo; de documentação da arte que se dispõe a mostrar; de manutenção e restauro das obras; de organização e administração dos cursos a serem oferecidos.

Todas essas partes do museu envolvem várias áreas de interesse que não apenas as artes plásticas; e é nessa direção que deve ser pensada a visita de alunos aos museus, com o objetivo de atender as diversas áreas de interesses.

Edgard Morin nos diz que "não há nada simples na natureza, só o simplificado" (2003, p. 178). A complexidade não tem respostas, mas é um desafio. Quando se decide mostrar o museu como uma instituição complexa, não são respostas definitivas que estamos em busca, mas sim em deixar algumas perguntas a serem pensadas, e assim, é possível manter a curiosidade sobre esse espaço. Ainda conforme Morin:

[...] o todo organizado é alguma coisa a mais que a soma das partes, porque faz surgir qualidades que não existiriam nessa organização; essas qualidades são "emergentes", ou seja, podem ser constatadas empiricamente, sem ser dedutíveis logicamente; essas qualidades emergentes retroagem ao nível das partes e podem estimulá-las a exprimir suas potencialidades. (MORIN, 2003, p. 180)

Essas qualidades emergentes que nos remete Morin é o que esperamos encontrar quando o museu é mostrado em toda a sua dimensionalidade. Todos os visitantes-alunos tomarão conhecimento de todas as partes necessárias para manter, nos 
dias atuais, um museu; entretanto, cada um terá a sua área de preferência e descobrirá que, mesmo que não tenha qualidades artísticas para exporem, ainda assim, poderá fazer parte do quadro de funcionários, atuando na área de seu interesse.

Pascal já dizia: "só posso compreender um todo se conheço, especificamente, as partes, mas só posso compreender as partes se conhecer o todo". Isso significa que abandonamos um tipo de explicação linear por um tipo de explicação em movimento circular, onde vamos das partes para o todo, do todo para as partes, para tentar compreender um fenômeno" (MORIN, 2003, p. 182).

Logo, conhecer um museu na contemporaneidade não se limita apenas a apreciar suas exposições e a história da arte, mas sim toda a movimentação interna dessa organização cultural, além de seus setores, necessários para alcançar os objetivos fundamentais dos museus, que são o de preservar, pesquisar e comunicar. No MARGS, como observado no seguinte organograma, as diferentes áreas de atuação são divididas em núcleos:

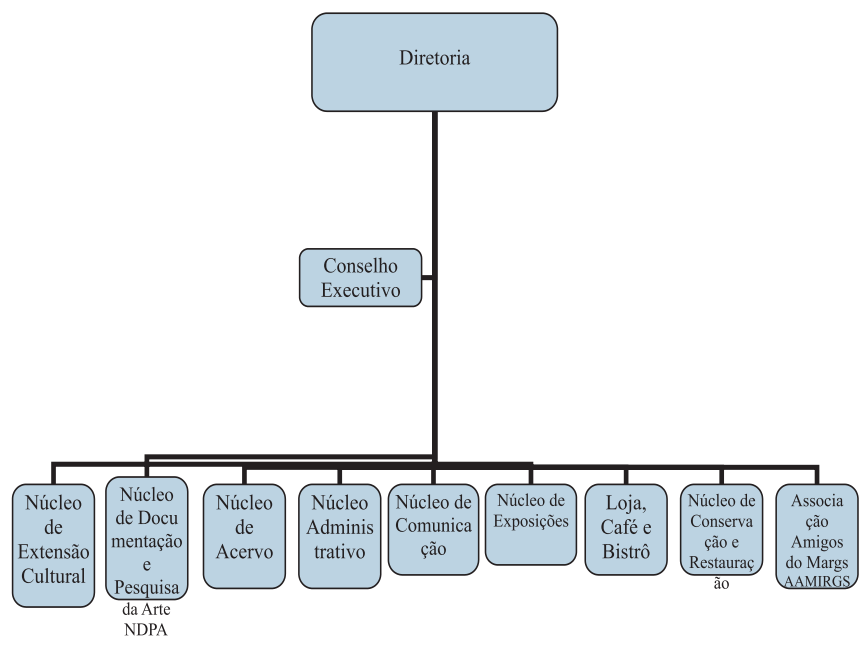

Fonte: Otávio Augusto Diniz Vieira 
É conhecendo esses diferentes núcleos que os alunos-visitantes poderão entender um pouco melhor sobre a complexidade desse museu. Ficarão, assim, muitas perguntas a ser respondidas, pois em uma visitação de uma hora seria impossível identificar todas os aspectos museológicos. E é assim que a complexidade surge como dificuldade, como incerteza e não como uma clareza e como resposta.

\section{Projeto de Intervenção}

O museu do MARGS oferece ao vistante quatro modalidades diferenciadas de visitação, que muitas vezes, na prática, se dão concomitantemente. Assim, não se pode dizer que essas ocorrem separadamente uma da outra. Amaral nos explica essas modalidades de visitação:

O primeiro tipo é a Visitação ao Museu, com roteiro dirigido ao conhecimento dos aspectos históricos, arquitetônicos e funcionais do MARGS; o segundo é o Roteiro entre formas e cores, que apresenta uma ou mais exposições com destaque para os modos como estes elementos formais se conjugam em uma obra de arte; uma outra modalidade é $A$ obra e o artista, que é uma visita dirigida a uma exposição dando destaque a informações sobre as obras expostas e o artista que as criou; finalmente a quarta e última modalidade de visitação é a chamada Motivação do olhar, um roteiro desenvolvido para o atendimento de crianças, visando motivá-las para a observação de obras de arte (AMARAL, 2008, p. 2).

A oportunidade de melhoria sugerida durante a visitação ao MARGS é a mescla dessas quatro modalidades; logo, o visitante conhecerá o museu como uma instituição cultural que é constituído por vários setores - todos eles fundamentais para que as exposiçôes possam ser mostrados - tendo então uma visão mais abrangente sobre a complexidade do museu, e não apenas sobre a exposição que está sendo mostrada no momento. 


\section{Atividade "Motivando o olhar".}

Transparências apresentadas em sala de aula na primeira fase do projeto.

- Sete melhores maneiras de não ver:

1 - saber o que quer ver

2- sentir-se mal por não entender

3 - procurar curiosidades

4 - preocupar-se com critérios de avaliação: bom ou mau

5- olhar para obras como se olha para ruínas. Visão

patrimonialística.

6 - olhar para dizer que viu

7 - ir para aprender, para memorizar

- Seis maneiras de ver:

1- despir-se de preconceitos

2 - ver como se fosse a primeira vez

3 - ver com olhar perplexo

4 - ver com atenção flutuante. Conselho de Freud: não fique atento demais.

5 - deixar a imaginação solta

6 - Não fazer a pergunta: O que é isso?

Em vez de: Por que ele fez isso?

Como ele fez isso? Significado e Contexto

Tal atividade teve como objetivo motivar o olhar dos futuros visitantes sobre aquele ambiente. Também foi discutido em sala de aula o modo como eles deveriam se portar no museu, principalmente na parte final da visitação, quando se reuniriam no café do museu, por esse ser um ambiente onde geralmente as escolas não frequentam.

No primeiro momento da visita, antes mesmo de entrar no museu, os alunos seriam recepcionados do lado de fora do MARGS, onde poderiam, junto com um monitor, conhecer a história do prédio e identificar os aspectos mais importantes da sua fachada. 


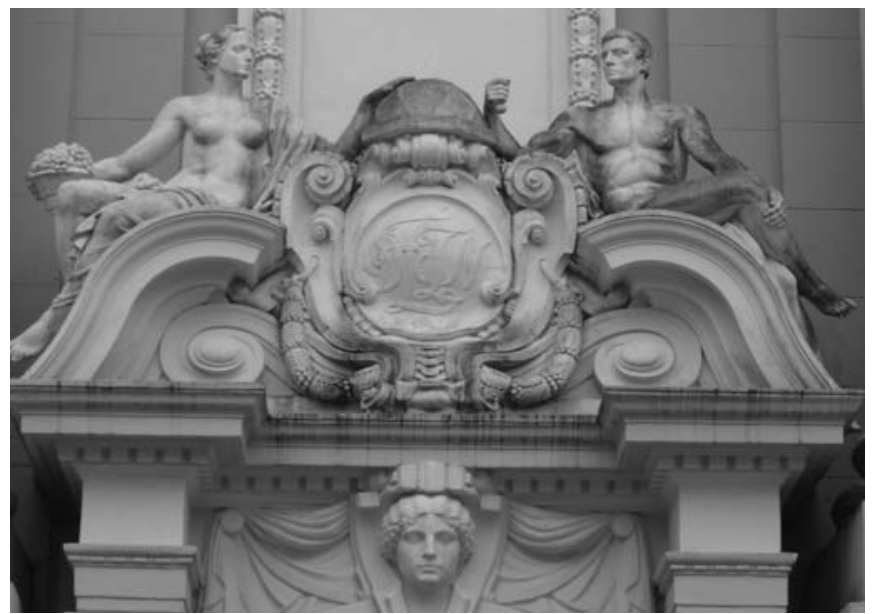

Foto: estátuas representando a Agricultura e o Comércio Fonte: Otávio Augusto Diniz Vieira

Para esse momento inicial de apresentação do edifício e de sua fachada, um estudo sobre a estatutária (estátuas da fachada) foi desenvolvido com base no livro de Doberstein: 1900-1920: estatuária e ideologia. Como exemplo, as duas figuras da entrada principal podem ser observadas na foto:

Segundo Doberstein:

Trata-se de uma representação de Demeter (Ceres) simbolizando a AGRICULTURA, e outra de Hermes (Mercúrio) representando o COMÉRCIO. [...] Demeter aparece apenas com a cornucópia da fecundidade, repleta de frutos da terra, enquanto Hermes porta tão somente um pequeno e discretíssimo saco de moedas na mão direita. Percebe-se uma acentuada tendência à idealização. Os corpos estão tão bem acomodados sobre as volutas da portada que fica a impressão de que a pose é de descanso permanente. (1992, p. 33)

Inicialmente o grupo dos alunos-visitantes recorreu alguns núcleos do museu - Núcleo de Documentação e Pesquisa em Arte, Núcleo de Extensão Cultural, Núcleo Administrativo e de Comunicação, Núcleo de Restauração e Conservaçao, Loja e Café - conhecendo assim as partes administrativas do MARGS; atividade que durou cerca de 40 minutos. 
Em seguida, foi realizada a visitação às exposições. Nesse momento, os alunos primeiramente ficaram livres para caminhar, olhar, sentir e dialogar com seus colegas sobre as exposições por cerca de 10 minutos; nesse momento não houve diálogo com o orientador. Em seguida, os alunos se reuniram na sala superior, onde a exposição Acervo Permanente do MARGS estava ocorrendo. Ali se encontraram com o orientador da exposição, e puderam então dialogar sobre as obras e aclarar as dúvidas surgidas; esse momento durou de 10 a 15 minutos.

O terceiro momento do projeto foi desenvolvido no café do MARGS, onde os alunos se reuniram e puderam sentar-se nas mesas e dialogar livremente, interagindo com outro ambiente cultural do museu, onde talmbém ocorrem exposições de pinturas e/ou fotografias.

Nesse espaço, foi entregue aos alunos, pela respectiva professora, duas pesquisas de avaliação da visitação. A primeira pesquisa foi uma questão aberta; e a segunda foram questôes estruturadas. As pesquisas com seus respectivos resultados estão a seguir.

\section{Pesquisas}

\section{1 - Questão aberta}

Resultado da pergunta aplicada no final da visitação, quando os alunos se sentaram e por alguns minutos puderam socializar no Café do MARGS, enquanto respondiam à questão proposta: Se você retormasse ao MARGS, em qual espaço gostaria de passar mais tempo? Comente.

Exposições - 39\% (7 alunos)

Restauração (terraço) - 22\% (4 alunos)

Futuras exposições - $16 \%$ ( 3 alunos)

Biblioteca $-11 \%$ ( 2 alunos)

Núcleo de Exposições - 6\% (1 aluno)

Café do MARGS - 6\% (1 aluno)

Total de Alunos: 18 


\section{2 - Questões estruturadas}

Ao preencher o questionário tenha em conta o grau de satisfação, conforme explicitado a seguir: 1 = Muito Insatisfeito, 2 = Insatisfeito, $3=$ Pouco Satisfeito, $4=$ Satisfeito e $5=$ Muito Satisfeito.

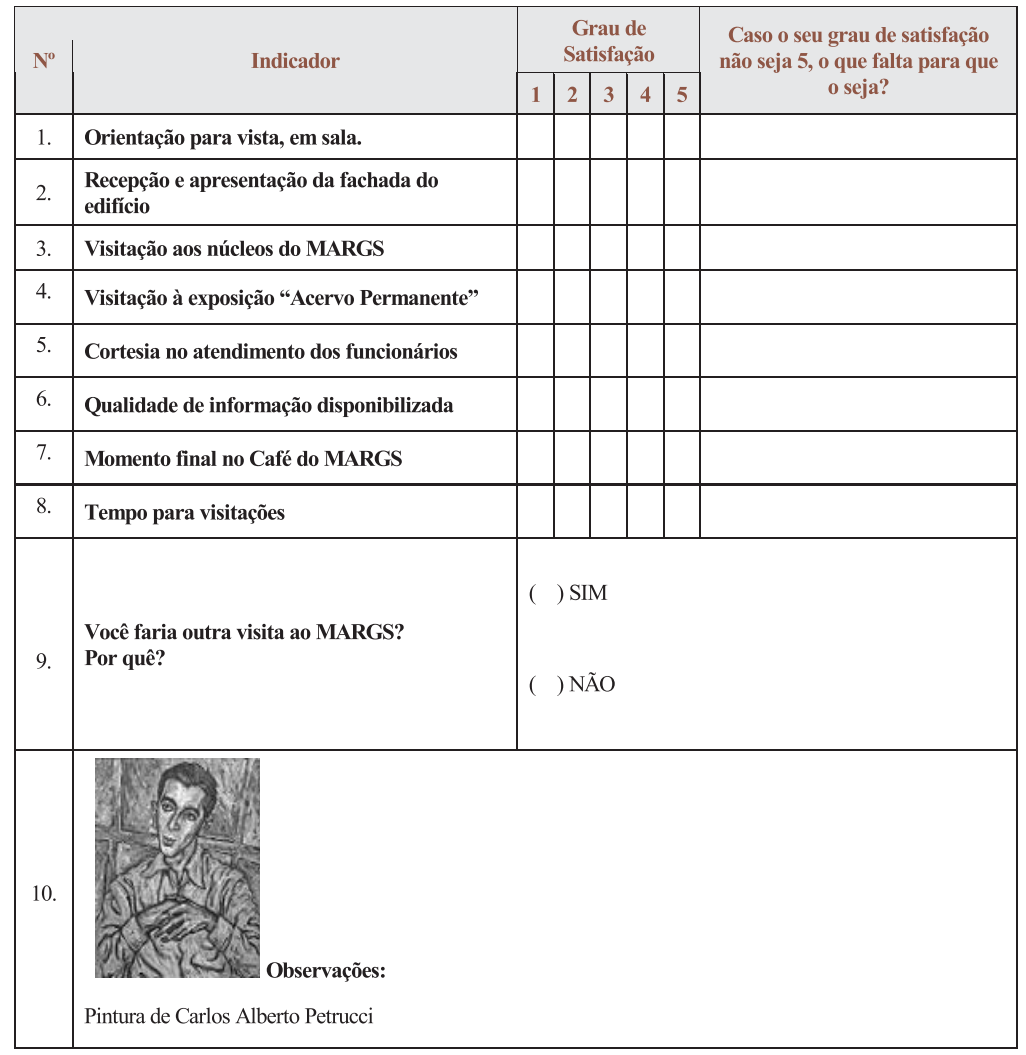

Um total de 12 alunos responderam o questionário. A porcentagem aqui apresentada é em relação a quantidade de alunos que deram grau máximo de satisfação (5)

1- Orientação para visita, realizada em sala de aula. - $91 \%$ (11 alunos)

2- Recepção e apresentação da fachada do edifício. - $\mathbf{7 5 \%}$ (9 alunos)

3- Visitação aos núcleos do MARGS. $100 \%$ (12 alunos)

4- Visitação à exposição "Acervo Permanente". $100 \%$ (12 alunos)

5- Cortesia no atendimento dos funcionários. 91\% (11 alunos)

6- Qualidade de informação disponibilizada. $\mathbf{6 6 \%}$ (8 alunos)

7- Momento final no Café do MARGS. $41 \%$ (5 alunos) 
8- Tempo para visitações. -

9- Você faria outra visita ao MARGS? -
75\% (9 alunos)

$\mathbf{1 0 0 \%}$ (12 alunos)

Os principais benefícios esperados desse projeto são, além de sensibilizar os alunos durante a visitação, tentando motivá-los para futuras visitaçôes a outros museus, também mostrar as mais variadas atividades que são realizadas internamente, criando assim um novo paradigma museológico, sobre aquele já formado, de que os museus são compostos apenas por salas de exposições.

\section{Discussão da pesquisa aberta}

A maioria do alunos respondeu que passaria mais tempo nas exposições. Esse foi um resultado já esperado, pois, devido à natureza desse modelo de visita, na qual a complexidade do museu é o principal aspecto abordado, vários outros setores carecem de tempo para a realização de um adequado recorrido, como é o caso das exposições. Porém, quando o aluno F. escreve que "cada quadro exige tempo para olhar”, observa-se que os alunos entenderam esse propósito da visita e que, caso quissessem, deveria retornar ao MARGS para poder observar as obras mais tranquilamente.

$\mathrm{O}$ aluno P. escreveu: "retornaria à sala azul, pois gostei dos quadros dos artistas internacionais, os detalhes são impressionantes".

O termo impressionismo surgiu devido a um dos primeiros quadros de Monet Impressão - Nascer do Sol, quando de uma crítica feita ao quadro pelo pintor e escritor Louis Leroy "Impressão, Nascer do Sol - eu bem o sabia! Pensava eu, justamente se eston impressionado éporque lá há uma impressão. E que liberdade, que suavidade de pincel! Um papel de parede é mais elaborado que esta cena marinba". A expressão foi usada originalmente de forma pejorativa, mas Monet e seus colegas adotaram o título, sabendo da revolução que estavam iniciando na pintura. (IMPRESSIONISMO, 2008)

Observa-se aqui uma interessante percepção do aluno, que entendeu muito bem como a nomenclatura "Impressionistas" foi utilizada durante a apresentação dos quadros que compõem a sala, e pôde, ele mesmo, usar o adjetivo "impressionantes". 
Alguns alunos que mencionaram o Núcleo de Restauração salientando a importância do trabalho ali realizado para a preservação do patrimônio histórico.

É interessante notar que alguns alunos responderam que gostariam de visitar as futuras exposições, como é o caso do aluno $\mathrm{L}$, quando responde que "Gostaria de olhar as exposições que serão abertas em breve [...]”. Percebe-se assim que a motivação para retornar ao MARGS foi definitivamente criada.

A biblioteca de artes plásticas, localizada no NDPA, é de inegável qualidade, e embora tenha havido pouco tempo para que os alunos pudessem explorá-la, ainda assim dois alunos se sensibilizaram pelo espaço e não deixaram de mencioná-la na resposta, justificando tal preferência da seguinte forma: "para entender melhor as obras, e só depois faria a visitação” (Aluno G).

Uma das alunas respondeu que gostaria de passar mais tempo no Núcleo de Exposição, que é um setor que tem estreito relacionamento com a área de relação pública.

O Café do MARGS foi mencionado uma vez, e, demonstrando estar motivado para futuras visitas, o aluno D. escreve: "para poder lanchar, e às exposições que não fomos dessa vez". Finalmente cito novamente o aluno L, quando responde: "Gostaria de olhar as exposições que serão abertas em breve, gostaria também de saber como é feita a reparação das obras e a montagem das exposições. Outra parte que achei bem interessante foi a biblioteca onde se guardam os arquivos e pastas com gravuras de obras de artistas brasileiros e internacionais."

Percebe-se, diante de tal resposta, que o aluno apresentou um alto nível de atenção em cada parte do museu, mostrando todo um interesse na abrangência das diversas atividades realizadas no espaço museológico, as quais são ignoradas pelos visitantes nos outros modelos de visitação.

Diante da variedade das respostas, com preferências distintas em relação aos espaços visitados do museu, pensamos que com tal visitação, baseada na complexidade, a qual abrange a visita à maior quantidade de espaços possíveis do museu, e que leve em consideração 
a clara diversidade de interesse dos alunos, é possível sensibilizar uma quantidade maior de alunos, e nao apenas àqueles que gostem de arte plásticas, como tem sido observado em visitações tradicionais.

O potencial de geraçao de ambiência do espaço museológico é, dessa forma, mais bem desenvolvido. Cada aluno terá gravado em sua memória o momento da visitação mais significativo para ele, podendo assim, consequentemente, interessar-se mais pelos museus em geral.

Acreditamos então que, para organizar uma visitação à um museu, não se deve apenas pensar no que se quer mostrar, em geral obras de arte, mas sim, pensar em todo o potencial educativo que tal espaço pode gerar; e que para tal, deve-se conhecer a realidade dos visitantes, para que a visita possa basear-se em uma relação de interação, entre o que é possível ensinar e o que se quer aprender.

\section{Análise da pesquisa estruturada}

Devido às más condições do tempo no dia da visitação, a recepção e a apresentação da história e da fachada do prédio, que estava prevista para acontecer do lado externo, não pôde ser realizada.

Os alunos sentiram falta de mais exposições no MARGS, pois a visitação ocorreu na exata semana de troca de exposições, logo, a maioria das salas de exposições do museu estavam desativadas, à espera da montagem da nova exposição.

O pouco tempo destinado às obras refletiu na menor informação disponibilizada sobre as mesmas, essa foi a razão do baixo grau de satisfação no ponto seis, que trata da qualidade da informação disponibilizada. É importante observar que os outros alunos que nao deram grau cinco para esse aspecto, deram então grau quatro ou três, demonstrando assim, apenas um parcial descontentamento.

Acredita-se, entretanto, que devido ao pouco tempo destinado à observação das obras, foi criada uma curiosidade nos alunosvisitantes, o que, talvez, venha a se refletir em futuras visitações. Privilegiou-se a visitação aos espaços do museu aos quais os visitantes dificilmente têm acesso nas visitas cotidianas. 
O baixo grau de satisfação do ponto sete, que trata do momento final realizado no Café do MARGS, foi justificado devido ao pouco tempo que os alunos ali permaneceram e ao alto preço dos produtos. É importante observar que esse éum espaço que as escolas normalmente nao visitam, devido ao seu suposto grau de formalidade; logo, foi decidido, previamente com os funcionários, por não alongar muito o tempo destinado a esse espaço, além do tempo necessário para responder à pergunta aberta, discutida no ponto anterior.

Como no ponto seis desse questionário, os outros alunos que não deram grau cinco decidiram então por um grau quatro ou três, demonstrando novamente apenas um parcial descontentamento.

O Café do MARGS é um espaço de certa forma privado, que tem um contrato diferenciado e que visa ao lucro. Notamos então, por intermédio de observaçôes e durante o processo de organização da visita, que a relação com as escolas visitantes parece ser um pouco mais limitada, seja devido ao baixo consumo dos alunos ou então ao suposto incômodo que eles possam vir a causar. Tal espaço é um ambiente que os alunos de escolas, principalmente públicas, não estão habituados a frequentarem e que, exatamente por isso, também pode e deve ser um local de aprendizado e novas experiências.

O ponto oito, que trata do tempo para visitações, ficou prejudicado, como esperado, devido ao curto tempo que é destinado às exposiçoes nesse modelo de visitação. Criou-se, entretanto, como dito anteriormente, uma curiosidade nos alunos, necessária para criar a vontade de realizar futuras visitações.

Duas observações feitas pelos alunos parecem revelantes e são aqui reproduzidas: "Os eventos que acontecem no MARGS poderiam ser divulgados em nossa escola e nos meios de comunicação" e "transporte para levar os alunos de volta à escola".

Logo, o MARGS sendo um museu público, tem a obrigação de trabalhar em prol da educação, recebendo e atendendo o maior número de pessoas possível, em particular os jovens de escolas públicas, que têm maior dificuldade financeira para locomover-se e realizar tais visitações. Fica aqui, então, duas sugestões, vindas 
dos próprios alunos: divulgar os eventos nas escolas públicas e adquirir um ônibus, fomentando assim a visitação ao museu. Entendemos, entretanto, todos os custos que tais realizaçóes acarretariam, mas esforços constantes nessa direção devem ser feitos.

\section{Considerações finais}

Durante as visitas realizadas pelas escolas ao MARGS, parece ser de vital importância que alguns aspectos do museu sejam incluídos nessas visitações. A apresentação da fachada e história do edifício serve como inicial agente motivador, para que mesmo antes que os alunos-visitantes entrem e comecem a recorrer as partes internas do museu, já de algum modo percebam a magnitude e importância de tal espaço.

Uma vez dentro do museu, devido aos mais diversos interesses que os alunos de Ensino Médio apresentam, é importante que eles observem outros aspectos além dos artísticos, visto que, embora esse seja a principal atração de qualquer museu, muitas vezes não é o principal interesse de alguns alunos.

Logo, mostrar toda a complexidade dos museus, desde a sua história arquitetônica até os aspectos administrativos, documentais e de pesquisa, essenciais para um bom e contíno funcionamento, é importante para criar, através do conhecimento do "todo" museológico, um interesse nao apenas ao museu visitado, mas à instituição Museu.

Foi apresentado nesta pesquisa o poder de geração de ambiência que tem os museus. Os espaços museológicos são espaços com potencial para ensinar muito mais do que a arte em si, eles também podem educar e sensibilizar os visitantes por intermédio de outros aspectos, como o administrativo, o histórico, o convívio social, entre outros.

Desejando valorizar a identidade local e motivar para futuras visitas, deve-se propor a passar aos jovems cidadãos a importância e complexidade dos trabalhos realizados no museu, que não é apenas o de expor as obras de arte. 


\section{Referências}

AMARAL, José Luiz. Como se orientarno MARGS. Palestra realizada durante o I Encontro de Orientadores do MARGS, 02 e 03 de abril de 2008.

BARRETO, Margarita. Turismo e legado cultural: as possibilidades do planejamento. 2 ed. Porto Alegre: Papirus, 2001.

BRITO, Alexandre. Revista do MARGS - Tempo Memória em movimento. Governo do Estado do Rio Grande do Sul. Secretaria de Estado da Cultura. MARGS. Publicação bimensal / Edição Especial. dezembro n $0,2007$.

COSTELLE, Roselane Jordão. Um pouco do mundo cabe nas mãos. Porto Alegre: Ed. da UFRGS, 2003.

DOBERSTEIN, Arnoldo Walter. Porto Alegre, 1900-1920: estatuária e ideologia. Porto Alegre: Secretaria Municipal de Cultura, 1992.

FUNARI, Pedro Paulo (Org.). Turismo e Patrimônio Cultural. São Paulo: Contexto, 2001.

MOLETTA, Vânia Beatriz Florentino. Turismo estudantil. Porto Alegre: SEBRAE/RS, 2003.

MORIN, Edgar. Ciência com Consciência. 7 ed. Rio de Janeiro: Bertrand Brasil, 2003.

IMPRESSIONISMO. Disponível em http://www.historiadaarte.com. br/impressionismo.html Acesso em 05 de maio 2008.

REGO, Nelson; SUERTEGARAY, Dirce ; HEIDRICH, Álvaro. Geografia e Educação - Geração de Ambiências. Porto Alegre: Ed da UFRGS, 2000. 